\title{
Models of Arctic-alpine refugia highlight importance of climate and local topography
}

\section{Niskanen, Annina}

2017-03

Niskanen , A , Luoto , M , Väre , H \& Heikkinen , R K 2017 , ' Models of Arctic-alpine refugia highlight importance of climate and local topography ', Polar Biology , vol. 40 , no. 3 , pp. 489-502 . https://doi.org/10.1007/s00300-016-1973-3

http://hdl.handle.net/10138/307064

https://doi.org/10.1007/s00300-016-1973-3

unspecified

acceptedVersion

Downloaded from Helda, University of Helsinki institutional repository.

This is an electronic reprint of the original article.

This reprint may differ from the original in pagination and typographic detail.

Please cite the original version. 


\section{Polar Biology \\ Models of arctic-alpine refugia highlight importance of climate and local topography --Manuscript Draft--}

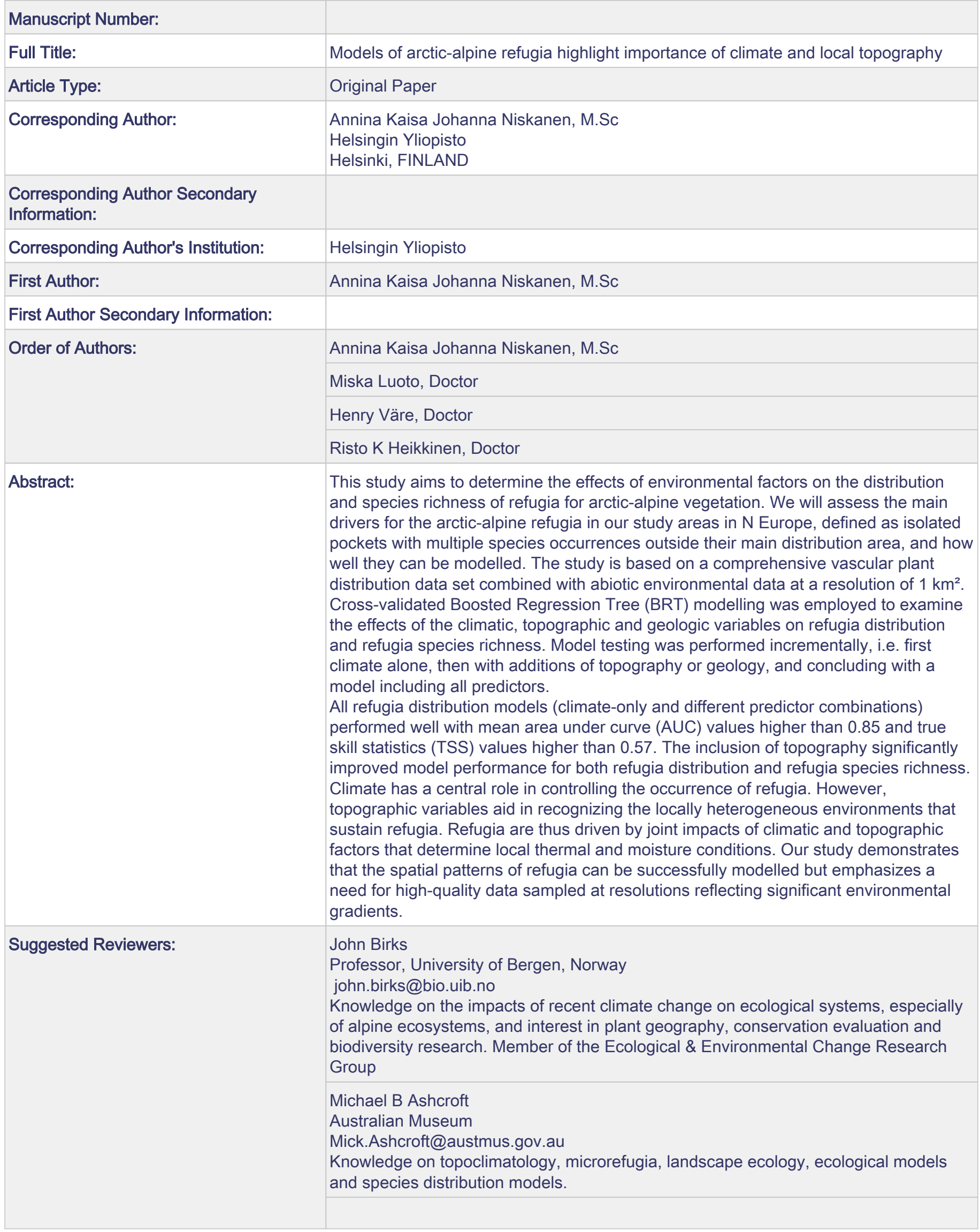


Niklaus E Zimmermann

Senior Scientist, Swiss Federal Research Institute WSL

niklaus.zimmermann@wsl.ch

Knowledge on macroecology, species

distribution models and climate change impacts on biodiversity.

Kristoffer Hylander

Professor, Stockholm University, Sweden

kristoffer.hylander@su.se

Research interests include the patterns and determinants of species richness and composition at different spatial scales, and the responses of northern species to climate change.

Mike P Austin

Honorary Fellow, CSIRO Ecosystem Sciences, Canberra, Australia

mike.austin@csiro.au

Research interests include species distribution and spatial modelling and climate change studies.

\section{Opposed Reviewers:}

Order of Authors Secondary Information: 


\section{$1 \quad$ Polar Biology}

\section{Models of arctic-alpine refugia highlight importance of climate and local topography}

3 Authors: Annina Niskanen¹, Miska Luoto ${ }^{1}$, Henry Väre², Risto Heikkinen³

4 Department of Geosciences and Geography, P.O. Box 64 (Gustaf Hällströmin katu 2a), FI-00014 University of 5 Helsinki, Finland ${ }^{1}$; Finnish Museum of Natural History, P.O. Box 7 (Unioninkatu 44), Room 131.1, University

6 of Helsinki, Finland²; Finnish Environment Institute, Natural Environment Centre, Mechelininkatu 34a, 00260

7 Helsinki, P.O. Box 140, Helsinki, Finland

8 Corresponding author: Annina Niskanen, annina.k.niskanen@helsinki.fi, +358054635706

$9 \quad$ Running title: Modelling arctic-alpine refugia

10 Word count (main text): 4016

11 Word count (abstract): 247

12 References: 59

13 Figures/tables: 7

\section{Supplementary material: 4}

\section{Abstract}

This study aims to determine the effects of environmental factors on the distribution and species richness of refugia for arctic-alpine vegetation. We will assess the main drivers for the arctic-alpine refugia in our study areas in $\mathrm{N}$ Europe, defined as isolated pockets with multiple species occurrences outside their main distribution area, and how well they can be modelled. The study is based on a comprehensive vascular plant distribution data set combined with abiotic environmental data at a resolution of $1 \mathrm{~km}^{2}$. Cross-validated Boosted Regression Tree (BRT) modelling was employed to examine the effects of the climatic, topographic and geologic variables on refugia distribution and refugia species richness. Model testing was performed incrementally, i.e. first climate alone, then with additions of topography or geology, and concluding with a model including all predictors. All refugia distribution models (climate-only and different predictor combinations) performed well with mean area under curve (AUC) values higher than 0.85 and true skill statistics (TSS) values higher than 0.57. The inclusion of topography significantly improved model performance for both refugia distribution and refugia 
species richness. Climate has a central role in controlling the occurrence of refugia. However, topographic variables aid in recognizing the locally heterogeneous environments that sustain refugia. Refugia are thus driven by joint impacts of climatic and topographic factors that determine local thermal and moisture conditions. Our study demonstrates that the spatial patterns of refugia can be successfully modelled but emphasizes a need for high-quality data sampled at resolutions reflecting significant environmental gradients.

Keywords: General Boosted Model; GBM; spatial modelling; species distribution models; refugium; highlatitude environments.

\section{INTRODUCTION}

Climate change is predicted to cause notable changes in high-latitude environments, causing fragmentation and structural changes in habitats and ultimately leading to local extinctions and range shifts of plant species (Ashcroft 2010; IPCC 2007; Root et al. 2003). Some species may, however, be able to persist in refugia (Skov and Svenning 2004). In general, refugia are considered as suitable locations for species to retreat to in unfavorable periods and re-disperse from if suitable environmental conditions return (Dobrowski 2011; Keppel et al. 2012). Projected climatic changes in high-latitude environments call for increased attention to the identification of locations that act as present-day refugia or could function as refugia in the future.

Two main lines of reasoning are relevant here. First, a number of studies call for the protection of contemporary and future refugia (Bush 1996; Noss 2001; Mawdsley et al. 2009) as they are increasingly considered as a means to reduce the impacts of environmental change on biota (Médail and Diadema 2009; Dobrowski 2011) and biodiversity (Barnosky 2008; Rull 2009; Ashcroft 2010; Vegas-Vilarrúbia et al. 2012). Second, identifying the main drivers of refugia occurrence and species richness, and developing models for these relationships, is of particular importance in the preservation of arctic ecosystems (Reside et al. 2013; Shoo et al. 2013) as the distribution of contemporary refugia can also provide decisive clues for determining the most probable locations of future refugia.

Despite growing interest in the supportive role of refugia in the face of climate change, our knowledge remains insufficient in regards to a number of research issues. In particular, refugia for cold-adapted 
species have not been well documented (Bennett and Provan 2008; Stewart et al. 2010) and there is great uncertainty regarding the conditions governing their subsistence (Dobrowski 2011; Moritz and Agudo 2013). The importance of filling this gap in knowledge is enhanced by the fact that there are no on-going attempts to quantify contemporary refugia in arctic-alpine northern Europe, a region likely to experience notable changes in climate (ACIA 2004). This study aims to fill in such research gaps by incorporating extensive data sets with modern geoinformatics and spatial modelling tools to investigate the spatial patterns of contemporary refugia and their predictability. For the purposes of this study, we define refugia as isolated pockets of multiple species occurring outside a main distribution area. Based on this definition we will model and quantify the effects of climatic, topographic and geologic variables on the distribution and species richness of refugia for arctic-alpine plant species outside their main range area, starting with baseline climate-only models and building up to more complicated models, ultimately including predictors from all three variable categories. To achieve this we analyzed an extensive data set collected in north-western Finland and Norway, a region where refugia may be expected to strongly influence current and future vegetation patterns.

\section{MATERIALS AND METHODS}

\section{Study area}

The study area is located in northern Fennoscandia between $67^{\circ} \mathrm{N}$ and $69^{\circ} \mathrm{N}$ (Fig. 1 a). The climate in the region is sub-arctic and strongly affected by its location at the edge of the Eurasian continent, the influence of the Polar Front and the warm North Atlantic current, and the proximity of the Scandes Mountains (Fig. 1 b: Tikkanen 2005; Aalto et al. 2014). Mean July temperature varies from $1.3{ }^{\circ} \mathrm{C}$ to $12.6{ }^{\circ} \mathrm{C}$ and mean annual precipitation from 423mm to 593mm (1981 - 2010 averages) (Aalto et al. 2014). Along with the noticeable climatic gradients, the area is characterized by strong topographic and geologic gradients. Elevational differences range from 72 to 1365 m.a.s.l. The vegetational gradient of the study area runs from spruce and Scots pine dominated forests in the south to mountain birch in the north, with tundra-like shrub-dominated vegetation above the treeline (Sormunen et al. 2010; Aalto and Luoto 2014). 


\section{Refugia species}

A vegetation data set consisting of $20811 \mathrm{~km}^{2}$ cells in north-western Finland served as the basis for this study. The species data was collected by professional and voluntary amateur botanists and refined using scientific literature and herbaria (Ryttäri and Kettunen 1997; Rassi et al. 2001). Two dependent variables were derived from the species data: (1) binomial refugia distribution and (2) refugia species richness.

Though refugia are species specific (Bennett and Provan 2008; Stewart et al. 2010), the favourable environmental conditions supporting refugia may overlap for several species (Keppel et al. 2012). Consequently, sites harbouring several refugia species simultaneously are potentially very valuable for future conservation planning. Arctic-alpine species (hereafter called refugia species) were inferred from our floristic data set as species with more than two thirds of their study area distribution in the arctic-alpine Scandes Mountains (Fig. 1; see Online Resource 1 for species list). This set of refugia species was then used to detect contemporary arctic-alpine refugia in the study region outside their main distribution area in the Scandes Mountains. As our focus was in building models for the refugia, the $1 \mathrm{~km}^{2}$ cells located in the Scandes Mountains (which were used to infer refugia species) were disregarded from the subsequent model building (grey points in Fig. 1). Consequently, a total of 1552 cells were included in the calibration of our refugia models modelling (white points in Fig. 1). From the retained 1552 cells we appointed those with observations of multiple ( $\geq 5$ ) refugia species as refugia cells. The presence of multiple refugia species is a way of repeatedly identifying them as refugia and enables us to determine the most important predictors.

\section{Environmental predictors}

We used an extensive environmental 1 x $1 \mathrm{~km}$ data grid matching the species data and encompassing the entire study area to quantify dominant refugia predictors. A total of 11 ecologically appropriate and theoretically meaningful climatic, geologic and topographic variables (Körner 1999; Skov and Svenning 2004; Dobrowski 2011; Scherrer and Körner 2011; Graae et al. 2012; Reside et al. 2013) were chosen for modelling both refugia distribution and species richness (Table 1). We assume refugia distribution to be linked to the physical 
environment represented by these variables and, consequently, refugial species to show distinct relationships with one or more of the environmental factors considered here (Guisan et al. 1998).

The climate data set, comprising of observations from 61 stations in northern Fennoscandia, was acquired from the national observation networks of Finland (Finnish Meteorological Institute), Sweden (Swedish Meteorological and Hydrological Institute 2012) and Norway (the Norwegian Meteorological Institute 2012). The temporal coverage corresponds to the recording period of the species data $(1971-2000)$. Three mean climatic variables were calculated from monthly mean temperature and precipitation values (see Aalto et al. 2014): (1) growing degree days (GDD3; growing conditions); (2) freezing degree days (FDD; overwintering conditions) and; (3) water balance (WAB; available moisture). Two variables describing extreme temperatures were constructed alongside mean conditions as they may be especially characteristic of high-latitude environments (Aalto et al. 2014). The predicted rapid increase in extreme temperature events (Meehl and Tebaldi 2004) make them increasingly relevant for studies of ecological systems (Pimm 2009). In our study, daily minimum and maximum temperatures were used to delineate annual measures of extreme absolute temperatures. Lowest absolute minimum temperatures $\left(T_{\min }\right.$; coolest within-cell sites) represent winter conditions, where colder temperatures are needed for the persistence of cold-adapted northern species. Lowest absolute maximum temperatures ( $T_{\max }$; the coolest within-cell sites within a warmer matrix) represent sites that remain relatively cool when the surrounding area warms up in the summer, i.e. conditions that are necessary for the survival of northern species under the warming climate.

Topography can also exert a strong influence on growing conditions and the distribution of potential refugia (Ackerly et al. 2010; Austin and Van Niel 2011; Scherrer and Körner 2011; Keppel et al. 2012). The topographic variables used here were based on an Aster -derived digital elevation model (DEM; spatial resolution $25 \mathrm{~m}^{2}$; Land Survey of Finland, 2013) and calculated following Aalto and Luoto (2014). Three topography-based variables were selected: (1) incoming potential solar radiation (surface temperature conditions (McCune and Keon 2002)); (2) topographic wetness index (TWI; availability of soil moisture from upslope areas (Beven and Kirky 1979)); and (3) slope angle (slope processes). These variables are good proxies for the microclimates of rugged terrain (Guisan and Zimmermann 2000; Dobrowski 2011) and geomorphological processes (Randin et al. 2009) affecting species distributions in high-latitude landscapes. 
Slope and TWI have also been found to be good predictors of soil moisture (Penna et al. 2009), which is a key driver of vegetation properties (le Roux et al. 2013).

Geology influences vegetation through soil properties (Guisan et al. 1998; Austin and Van Niel 2010). Three geologic variables were chosen for this study: (1) calcareousness (soil $\mathrm{pH}$, shown to improve the predictive power of species distribution models (Dubuis et al. 2012)), (2) soil diversity (variability of growing substrate: rock, sand, peat, till) and (3) rock cover (cliffs, rocky outcrops, scree; considered here as its own variable as it can be significant in predicting species distributions in harsh environments (Guisan et al. 1998)). The geological predictors used here were reclassified from a digital database (Geological Survey of Finland: 2010) and transformed following Aalto and Luoto (2014).

\section{Data analysis}

We combined species distribution data with environmental predictors to determine the drivers of refugia and their species richness in our study area. Predictor and response variable relationships were quantified using boosted regression tree (BRT) modelling, a form of regression capable of modelling complex nonlinear functions (Elith et al. 2008). Comparative analyses have rated BRT performance highly (Elith et al. 2006; Heikkinen et al. 2012). BRTs simultaneously use numerous trees and consider all predictors as well as interactions to improve model performance and predictive ability (Elith et al. 2006, 2008; De'ath 2007; Leathwick et al. 2008). BRTs compute the relative influence of each variable based on capacity to reduce overall model deviance and contribution to predictive ability. Higher relative influence values point to stronger effects of the predictor on the response variable (De'ath et al. 2007; Elith et al. 2008). In the first phase of the modelling process, models were calibrated using only $1 \mathrm{~km}^{2}$ grid cells with available vegetation data. All statistical analyses were performed using the statistical software R (version 3.0.2; R Foundation for Statistical Computing, Vienna, AT).

The BRT models (interaction depth $=4$, number of iterations/ trees $=3000$ ) were run using the gbm -package (Ridgeway 2013). Models were built to assess the importance of different environmental variable groups and to evaluate the relative influence of individual variables on refugia. The response variables, (a) refugia distribution and (b) refugia species richness, were fitted with identical sets of environmental predictors (Fig. 2) using Bernoulli and Poisson distributions, respectively. 

and le Roux et al. $(2012 ; 2013)$ to assess model transferability: projections were cross-validated with 999 runs, each time selecting a different $70 \%$ random data sample while verifying model accuracy against the remaining $30 \%$. We assessed the predictive power of the refugia distribution models by comparing the observed and predicted refugia occurrences by calculating the mean values of the area under the curve of a receiver operating characteristic plot (AUC; Fielding and Bell 1997) and the true skill statistics (TSS; Allouche et al. 2006) based on the evaluation runs. AUC values generally range from a random (AUC 0.5) to a perfect fit (AUC 1.0), with AUC values higher than 0.7 deemed a fair fit (see Swets 1988). A TSS value of 1 indicates perfect agreement; zero or below indicates a performance no better than random (Allouche et al. 2006). The models for refugia species richness were examined with the same cross-validation procedure but using Spearman's rho $(\rho)$ analysis. A non-parametric Wilcoxon's test was employed to examine whether explanatory power and predictive accuracy differed significantly between models.

With the exception of temperature extremes $\left(T_{\max }\right.$ and $\left.T_{\min }\right)$ and soil diversity, all variables are expressed as mean values, as calculated for the $1 \mathrm{~km}^{2}$ cells included in the study. Some correlations exist between the extreme temperature variables, GDD3 and WAB. Slope is also strongly correlated with $T W I$, as the former is used to calculate the latter (Online Resource 2).

In the second phase of the modelling process, we produced final prediction maps to illustrate the spatial predictions of the contemporary refugia for a wider area, i.e. the region in which the $15521 \mathrm{~km}^{2}$ cells used in model calibration are embedded. Here, the derived models were fitted to the environmental data covering the entire study area with $1 \mathrm{~km}^{2}$ grid cells ( $\mathrm{n}=25766$ ), thus enabling us to predict refugia occurrence for the whole area.

\section{RESULTS}

\section{Refugia distribution}

We identified $1091 \mathrm{~km}^{2}$ grid cells harbouring refugia based on the species data available for our study area (Fig. 3). Refugia occurrence resembles a proximal distribution with few outliers situated diffusely in the south, thus showing a gradual decrease in refugia with distance to the main distribution area (Fig. 3). 

predictor variables are fairly good at predicting refugia distribution (Fig. 4a). Model TSS values demonstrate a moderately good explanatory power for the studied variables (Allouche et al. 2006). However, statistically significant differences between the models were evident. Adding topography to the climate-only model significantly improved predictive power, making the climate + topography model (Fig. 4a ii) the best combination of predictors for refugia distribution according to AUC values. The full model (Fig. 4a iv), however, has the highest mean TSS value. Additions of geologic variables improve the climate model only according to TSS values (Fig. 4a iii).

The importance of climatic predictors is pronounced (Fig. 5). WAB was constantly shown as the most influential variable within all models of refugia distribution, with areas of high $W A B$ promoting extreme habitats (Online Resource 4: Fig. 1). Refugia are located in $1 \mathrm{~km}^{2}$ cells which have sites that become neither too hot in summers nor too cold during winters, i.e. they host less extreme environments in regards to $T_{\max }$ and $T_{\min }$ (Fig. 5; Online Resource 4: Fig. 1). Correlations are also evident between refugia distribution and topographic predictors. The importance of slope indicates that refugia are more often found in steeper than flatter terrain (Fig. 5; Online Resource 4: Fig. 1). Improvements to model performance from the inclusion of geologic variables were indistinct and minor (Fig. 5). Model projections for refugia occurrence across the entire study area are visualized in Figure 6. These prediction maps mirror results seen in Figures 4a and 5. They visually demonstrate climatic significance at this scale of analysis, similarities between models, and a slight increase in the detail of the spatial pattern of refugia distribution, especially to the south, resulting from the addition of local topographic predictors to climate-only models.

\section{Refugia species richness}

The environmental variables studied here fare better in explaining refugia species richness than refugia distribution (mean Spearman's rho ( $\rho$ ) values 0.53 and 0.37, respectively) (Online Resource 4: Fig. 2). All mean Spearman's rho $(\rho)$ values are higher than 0.50 , suggesting that all variable combinations are fairly good predictors of refugia species richness with marginally significant differences between models (Fig. 4b). The sole exception to significantly improve predictive power was the addition of topography to the climate model (Fig. $4 \mathrm{~b}$ ii). 
212 important variable in the full model. $T_{\max }$ is the most important climatic variable when effects of topography are

213 not directly accounted for, with more species favouring less extreme temperatures in regards to both extreme

214 temperature variables. The topographic variable slope has the most relevant influence on refugia species 215 richness, followed by the effects of climatic conditions (Fig. 5). A clear threshold exists with topographically 216 heterogeneous areas where slopes steeper than $15^{\circ}$ display greater refugia species richness (Online Resource 4 : 217 Fig. 2). The geological variables consistently showed the weakest overall explanatory power for refugia species 218 richness (Fig. 5).

\section{DISCUSSION}

To decipher where refugia might be located in the future and why, we must develop robust models to predict their current distributions and ascertain the key drivers underlying them. This study provides promising results for this task as we were successfully able to locate and model contemporary refugia, as well as infer factors affecting their suitability for multiple refugia species based on climatic, topographic and geologic parameters. Our results suggest that useful predictive models for refugia distribution can be developed by relating key environmental features with species occurrences, thus highlighting the significance of spatially explicit species' data and reliable, fine-resolution climate and environmental data (Austin and Van Niell 2010, 2011). We echo notions put forth by Luoto and Heikkinen (2008) and Austin and Van Niell (2011) concerning the inclusion of topography leading to more robust estimates of species distributions.

Noticeable trends and the pronounced contributions of certain variables enabled us to distinguish suitable physical drivers of contemporary refugia. Trends included refugia preference to environments differing from regional means (e.g. Taberlet and Cheddadi 2002; Ackerly et al. 2010), locations with steep slopes or moist soil conditions (e.g. Rull 2009; Dobrowski 2010), cooler or shorter growing seasons and coolest within-cell meso-climates (e.g. Dobrowski et al. 2010), all landscape features supporting refugia development and boosting refugial biodiversity in the studied arctic-alpine region. Variables indicating suitable moisture conditions and the presence of relatively cool sites (Olson et al. 2012) and slopes were constantly identified as the most controlling and influential factors for both refugia distribution and species richness with a pooled variable influence between $63-79 \%$ in all models. 
239 prediction maps show that the probabilities of refugia occurrence over the whole study region are mainly low $240(<5 \%)$. This, along with the high relevance of climatic variables, reinforces the cautionary remarks on how well 241 climate trajectories will enable the re-dispersal of refugia species (Hannah et al. 2014). Still, refugia provide one of the most promising means to support species survival under adverse climates (Birks and Willis 2008; Keppel et al. 2012). In our results, all climate-only model predictions were improved by the incorporation of topography and the importance of the most influential variables relies on the inclusion of both climatic and topographic predictor sets. This provides clear support for the complementary significance of local factors for refugial persistence (Sormunen et al. 2010). Moisture conditions were the most important predictors of refugia distribution while the effects of slope was integral to explaining refugia species richness, suggesting that while climate is key in controlling where refugia occur, topographic factors enable the persistence of multiple species in these refugia.

Cells with refugia in our study area are characterized by moister conditions resulting from high precipitation or low evapotranspiration, which is in agreement with a number of earlier studies (Armbruster et al. 2007; Thomas Fickert 2007; Ackerly et al. 2010). Growing season temperatures were of higher relative importance than overwintering temperatures, suggesting that the avoidance of summer time temperature highs is critical for arctic-alpine refugia. Despite the significance of mean growing conditions, the refugia in our study appear to be more affected by climatic extremes. The relative influence of growing conditions is surpassed by the presence of relatively cooler sites in all models, possibly displaying the climatic stability offered by more oceanic climates (Aalto et al. 2014) and reflected in the proximal distribution of the refugia. These results, concordant with research in different climatic conditions (Noss 2001; Shoo et al. 2010; Ashcroft and Gollan 2013), show that refugia may thus be more susceptible to changes in climatic extremes than fluctuations in seasonal temperatures. Refugia provide species with cooler locales when temperatures reach their maximum: lowest maximum temperatures of refugia are, on average, $2.2^{\circ} \mathrm{C}$ cooler than non-refugial cells (Online Resource 2).

Topography has a clear effect on the extreme temperatures of the region (Aalto et al. 2014), seen in our results through the importance of the lowest maximum temperatures when topography is not taken into account. Our results showcase the importance of refugial cooling effects for arctic-alpine species, possibly 
resulting in increased temperature gradients and thereby leading to more diverse habitats (Fridley 2009; Ashcroft 2010). Consequently, the importance of refugia can be seen as two-fold: protecting species from environmental change as well as increasing environmental diversity.

Steeper slopes provide ideal habitats for many refugia species (Online Resource 4: Figs. 1 and 2). Slope-related factors have been shown to effect biodiversity (Körner 2005; Bennie et al. 2006), possibly manifesting through topographic influence on climate, such as steeper slopes decoupling local climates from the regional (Hampe et al. 2013). The role of steep landforms in the study area as well as in the adjacent Scandes Mountains may become increasingly vital for species persistence in the future. This issue is linked with the question on how earth surface processes (ESPs; e.g. active geomorphic processes related to slope) might influence refugia, especially as they have been shown to improve species richness and distribution model accuracy for arctic-alpine species in particular (Luoto and le Roux 2014). Improvements to model performance from the inclusion of geologic predictors were minor and indistinct, suggesting that geologic data is not essential for refugia modelling at the meso-scale (here, resolution of $1 \mathrm{~km}^{2}$ ) (Anderson and Ferree 2010). Another potential explanation is that the effect of geological conditions may be imperative only for individual refugia species and thus remain undetected in multi-species analyses.

More generally, due to the spatial scale of this study it cannot be determined whether the significance of the factors deemed here as important for refugia is direct or indirect. Though both coarse and fine scale processes are relevant for assessing changes in species' distributions under changing climates, fine scale analysis would capture more precise effects of current and forthcoming changes on biota. Refugia species richness was more accurately predicted than occurrence, emphasizing the importance of considering refugia in terms of biodiversity conservation (Taberlet and Cheddadi 2002) and yet, adversely, underlining difficulties in locating refugia for individual species and the need to prioritise species at greatest risk (Skov and Svenning 2004). Our results support the notion that single refugia are not necessarily suitable for multiple at-risk species, so potential differences between refugia must be carefully considered.

The moderate explanatory power of the refugia distribution models might be explained by issues of temporality and spatiality: firstly, our models do not capture refugia dynamics (see Hannah et al. 2014) and secondly, occurrences of some refugia, particularly those inhabited by threatened species or including 
particularly sensitive habitats, may be governed by factors operating at finer scales than those employed here (Brown 2010). Though our use of meso-scale climate data goes some way in addressing issues of scale, our quantification of contemporary refugia relies on the identification method used, and as such cannot be used to address issues of long-term climate change (Ashcroft et al. 2012). Refugia connectivity is greater in areas closer to the main distribution area (Fig. 3), but whether this is due to limitations by environmental conditions or poor species' dispersal ability is difficult to judge. The ability of species to disperse into previously unoccupied $e x$ situ refugia should also be addressed, especially in light of the proximal nature of refugia occurrence in the area.

\section{CONCLUSIONS}

Climate alone has significant control on arctic-alpine plant refugia, though refugia species also appear to favour topographically heterogeneous environments. Modifications to broader environmental conditions through local features create fundamental environmental conditions that support refugia species, such as cooler climates resulting from a high water balance, as well as steep slopes and avoidance of extreme temperatures. As predictor effects on refugia species richness are bound to include species-specific responses, it is important to predict which species are most likely to be restricted to refugia in the future. Our results provide interesting avenues for further research, in which finer scale species data combined with measures of local climate, topography and other appropriate variables could give a more detailed outlook on the futures of these arctic-alpine species. However, already the findings of this study demonstrate the importance of appropriately scaled species' and environmental data at suitable resolutions and, by mapping contemporary refugia, provide a template for developing a better understanding of the processes governing refugia in changing arctic-alpine landscapes.

\section{Acknowledgements}

A. Niskanen was funded by the Doctoral school of Geosciences and Nordenskiöld samfundet. We acknowledge funding from the Academy of Finland (The Finnish Research Programme on Climate Change, Project Number 1140873). We would like to thank the Finnish Museum of Natural History as one of the main contributors of the vegetation data and Juha Aalto for helping with gathering the environmental data and data analysis. 
Additional supporting information may be found in the online version of this article:

Online Resource 1 List of the refugia species (species with more than two thirds of their study area distribution occurring in the arctic-alpine Scandes Mountains) used in this analysis

Online Resource 2 Variable correlation matrix showing Spearman's rho $(\rho)$ values between explanatory variables

Online Resource 3 Table showing variable coefficients

Online Resource 4 Response curves predicted by the full models for refugia distribution (Fig. 1) and refugia species richness (Fig. 2)

\section{References}

Aalto J, le Roux PC, Luoto M (2014) The meso-scale drivers of temperature extremes in high- latitude Fennoscandia. Clim Dyn 42:237-252

Aalto J, Luoto M (2014) Integrating climate and local factors for geomorphological distribution models. Earth Surf Process Landforms DOI: 101002/esp3554

Ackerly DD, Loarie SR, Cornwell WK, Weiss SB, Hamilton H, Branciforte R, Kraft NJB (2010) The geography of climate change: implications for conservation biogeography. Diversity Dist 16(3):476-487

ACIA (2004) Impacts of a Warming Arctic: Arctic Climate Impact Assessment ACIA Overview report. Cambridge University Press

Allouche O, Tsoar A, Kadmon R (2006) Assessing the accuracy of species distribution models: prevalence, kappa the true skill statistic (TSS). J Appl Ecol 43(6):1223-1232

Anderson MG, Ferree CE (2010) Conserving the stage: climate change and the geophysical underpinnings of species diversity. PLoS One 5(7):e11554 DOI:10.1371/journal.pone.0011554

Ashcroft, MB (2010) Identifying refugia from climate change. J Biogeogr 37:1407-1413

Ashcroft MB, Gollan JR (2013) Moisture, thermal inertia, and the spatial distributions of near-surface soil air temperatures: Understanding factors that promote microrefugia. Agr Forest Meteorol 176:77-89

Ashcroft MB, Gollan JR, Warton DI, Ramp D (2012) A novel approach to quantify and locate potential microrefugia using topoclimate, climate stability, and isolation from the matrix. Glob Chang Biol 18(6): 1866-1879

Austin MP, Van Niel KP (2011) Impact of landscape predictors on climate change modelling of species distributions: a case study with Eucalyptus fastigata in southern New South Wales, Australia. J Biogeogr 38:9-19

Austin MP, Van Niel KP (2010) Improving species distribution models for climate change studies: variable selection and scale. J Biogeogr 38(1):1-8

Barnosky AD (2008) Climatic change, refugia, and biodiversity: where do we go from here? An editorial comment. Clim Change 86(1-2):29-32

Bennett KD, Provan J (2008) What do we mean by 'refugia'? Quat Sci Rev 27(27-28):2449-2455

Bennie J, Hill MO, Baxter R, Huntley B (2006) Influence of slope and aspect on long-term vegetation change in British chalk grasslands. J Ecol 94(2):355-368 
Beven KJ, Kirkby MJ (1979) A physically based, variable contributing area model of basin hydrology. Hydro Sci Bull 24(1):43-69

Birks HH (2008) The Late-Quaternary history of arctic and alpine plants. Plant Ecol Divers 1(2): 135-146

Brown MJ (2010) Landscape Scale Conservation Planning in Tasmania. The Spatial Identification of Contemporary Refugia. NRM South. http://dpipwe.tas.gov.au/Documents/NRMRefugiaReportApril2010.pdf. Accessed 06 May 2014

Bush MB (1996) Amazonian conservation in a changing world. Biol Cons 76:219-228

De'Ath G (2007) Boosted trees for ecological modeling and prediction Ecology 88(1):243-251

Dobrowski SZ (2011) A climatic basis for microrefugia: the influence of terrain on climate. Glob Chang Biol 17(2):1022-1035

Dubuis A, Giovanettina S, Pellissier L, Pottier J, Vittoz P, Guisan A (2012) Improving the prediction of plant species distribution and community composition by adding edaphic to topo-climatic variables. J Veg Science 24:593-606

Elith J, Graham CH, Anderson RP, Dudík M, Ferrier S et al (2006) Novel methods improve prediction of species' distributions from occurrence data. Ecography 29:129-51

Elith J, Leathwick JR, Hastie T (2008) A working guide to boosted regression trees. J Anim Ecol 77(4):802-813

Fielding AH, Bell JF (1997) A review of methods for the assessment of prediction errors in conservation presence/absence models. Environ conserve 24(01):38-49

Graae BJ, De Frenne P, Kolb A, Brunet J, Chabrerie O, Verheyen K, Pepin N, Heinken T, Zobel M, Shevtsova A, Nijs I, Milbau A (2012) On the use of weather data in ecological studies along altitudinal and latitudinal gradients. Oikos 121(1):3-19

Guisan A, Theurillat J-P, Kienast F (1998) Predicting the potential distribution of plant species in an alpine environment. J Veg Sci 9:65-74

Guisan A, Zimmermann NE (2000) Predictive habitat distribution models in ecology. Ecol model 135(2):147-186

Hampe A, Rodríguez-Sánchez F, Dobrowski S, Hu FS, Gavin DG (2013) Climate refugia- from the LGM to the 21st century. New Phytol 197:16-18

Hannah L, Flint L, Syphard AD, Moritz MA, Buckley LB, McCullough IM (2014) Fine-grain modeling of species' response to climate change: holdouts, stepping-stones, and microrefugia. Trends Ecol Evol 29(7):390-397

Keppel G, Van Niel KP, Wardell-Johnson GW, Yates CJ, Byrne M, Mucina L, Schut AGT, Hopper SD, Franklin SE (2012) Refugia: identifying and understanding safe havens for biodiversity under climate change. Global Ecol Biogeogr 21(4):393-404

Körner C (2005) The green cover of mountains in a changing environment. In: Huber UM, Bugmann HKM, Reasoner MA (eds) Global Change and Mountain Regions. Springer Netherlands, pp 367-375

le Roux PC, Aalto J, Luoto M (2013) Soil moisture's underestimated role in climate change impact modelling in low-energy systems. Glob Chang Biol 19(10):2965-2975

Luoto M, le Roux PC (2014) Earth surface processes drive the richness, composition and occurrence of plant species in an arctic-alpine environment. J Veg Sci 25:45-54

Mawdsley JR, O’Malley R, Ojima DS (2009) A Review of Climate-Change Adaptation Strategies for Wildlife Management and Biodiversity Conservation. Conserv Biol 23(5):1080-1089

McCune B, Keon D (2002) Equations for potential annual direct incident radiation and heat load. J Veg Sci 13:603-606

Médail F, Diadema K (2009) Glacial refugia influence plant diversity patterns in the Mediterranean Basin. J Biogeogr 36(7):1333-1345

Meehl GA, Tebaldi C (2004) More intense, more frequent, and longer lasting heat waves in the $21 \mathrm{st}$ century. Science 305(5686):994-997

Moritz C, Agudo R (2013) The future of species under climate change: resilience or decline? Science 341:504508

Noss RF (2001) Beyond Kyoto: Forest Management in a Time of Rapid Climate Change. Conserv Biol 15(3):578-590

Olson D, DellaSala DA, Noss RF, Strittholt JR, Kass J, Koopman ME, Allnutt TF (2012) Climate Change Refugia for Biodiversity in the Klamath-Siskiyou Ecoregion. Nat Area J 32(1):65-74

Penna D, Borga M, Norbiato D, Dalla Fontana G (2009) Hillslope scale soil moisture variability in a steep alpine terrain. J Hydrol 364(3-4):311-327

Pimm, SL (2009) Climate disruption and biodiversity. Curr Biol 19(14):595-601 
Rassi P, Alanen A, Kanerva T, Mannerkoski I (eds) (2001) The 2000 red list of Finnish species. Ministry of the Environment, Finnish Environment Institute, Helsinki

Rin CF, Engler R, Norm S, Zappa M, Zimmermann NE, Pearman PB, Vittoz P, Thuiller W, Guisan A (2009) Climate change and plant distribution: local models predict high-elevation persistence. Glob Chang Biol 15(6):1557-1569

Reside EA, VerWal J, Phillips BL, Shoo LP, Dan BJA, Rosauer F, Justin A, Welbergen, S F C Moritz, Harwood TD, Kristen BM, Williams J, Hugh S, Williams SE (2013) Climate change refugia for terrestrial biodiversity: Defining areas that promote species persistence ecosystem resilience in the face of global climate change. National Climate Change Adaptation Research Facility, Gold Coast.

Heikkinen RK, Marmion M, Luoto M (2012) Does the interpolation accuracy of species distribution models come at the expense of transferability? Ecography 35:276-288

Rull, V (2009) Microrefugia J. Biogeogr 36(3):481-484

Ryttäri T, Kettunen T (1997) Uhanalaiset kasvimme. Suomen Ympäristökeskus, Kirjayhtymä Oy, Tampere.

Scherrer D, Körner C (2011) Topographically controlled thermal-habitat differentiation buffers alpine plant diversity against climate warming. J Biogeogr 38(2):406-416

Shoo LP, Storlie C, Williams YM, Williams SE (2010) Potential for mountaintop boulder fields to buffer species against extreme heat stress under climate change. Int J Biometeorol 54:475-478

Shoo LP, Hoffmann AA, Garnett S, Pressey RL, Williams YM, Taylor M, Falconi L, Yates CJ, Scott JK, Alagador D, Williams SE (2013) Making decisions to conserve species under climate change. Clim Change 119(2):239-246

Stewart JR, Lister AM, Barnes I, Dalen L (2010) Refugia revisited: individualistic responses of species in space and time. Proc R Soc B 277(1682):661-671

Skov F, Svenning JC (2004) Potential impact of climate change on the distribution of forest herbs in Europe. Ecography 27:366-380

Sormunen H, Virtanen R, Luoto M (2011). Inclusion of local environmental conditions alters high-latitude vegetation change predictions based on bioclimatic models. Polar Biol 34:883-897

Swets K (1988) Measuring the accuracy of diagnostic systems. Science 240:1285-1293

Taberlet P, Cheddadi R (2002) Quaternary refugia and persistence of biodiversity. Science 297(5589): 2009-2010

Root TL, Price JT, Hall KR, Schneider SH, Rosenzweig C, Pounds JA (2003) Fingerprints of global warming on wild animals and plants. Nature 421(6918):57-60

Tikkanen, M (2005) Climate. In: Seppälä M (ed) The physical geography of Fennoscandia. Oxford University Press, Oxford

Vegas-Vilarrúbia T, Nogué S, Rull V (2012) Global warming, habitat shifts and potential refugia for biodiversity conservation in the neotropical Guayana Highlands. Biol Cons 152: $159-168$

\section{Figure captions}

Fig. 1 The location and average temperature conditions (1971 - 2000: Finnish Meteorological Institute) of the study area in northern Fennoscandia with the locations of the sites with available plant distribution data: sites within the Scandes Mountains (dark grey points) were used to infer refugia species based on species distribution data (white points) and were subsequently excluded from analysis. The dashed line in the main map shows the study area subset seen in Fig. 3

Table 1 Descriptions of the environmental variables used in this study showing mean, minimum (Min) and maximum (Max) values 
Fig. 2 The structure of the models (i. - iv.) used to explain (a) refugia distribution and (b) refugia species richness

Fig. 3 The locations of the refugia (black points) in relation to the three most influential variables: (a) mean water balance $(W A B: \mathrm{mm}),(\mathrm{b})$ lowest maximal temperatures $\left(T_{\max }:{ }^{\circ} \mathrm{C}\right)$ and $(\mathrm{c})$ mean slope (Slope: degrees). The subset of the study area used in this visualization can be observed in the dashed line in the main map of Fig. 1

Fig. 4 Model accuracy in a) predicting refugia occurrence. Mean AUC (area under the curve of a receiver operating characteristic plot), TSS (true skill statistic) and Wilcoxon signed rank test p-values indicating change in the models predictive ability when adding either or both the topography/geology group to the climate model; and, b) predicting refugia species richness. Spearmans rank correlation coefficients (rs) and Wilcoxon signed rank test p-values indicating change in the models predictive ability when adding either or both the topography/geology group to the climate model. Change in predictive ability is indicated by asterisks. $* * *$ Highly significant change in predictive ability $(\mathrm{p}<0.001)$; $* *$ significant change $(\mathrm{p}<0.01)$; $*$ marginally significant change $(\mathrm{p}<0.05)$; ns, no significant change

Fig. 5 Variable influence (\%) for all BRT models (i - iv) for refugia distribution (a) and refugia species richness (b). The y-axis for each panel shows the relative influence of each variable within the model. Clim., Topo. and Geo. indicate the individual variables comprising the climatic, topographic and geologic factors. High relative influence corresponds to a strong influence of a predictor on the response variable

Fig. 6 The predicted occurrence of refugia across the whole study area using (a) climatic; (b) climatic and topographic; (c) climatic, topographic and geologic variables. Red indicates cells where model predictions indicate a high probability of refugia occurrence; blue specifies cells where the model predicts a low probability of refugia occurrence. Black marks indicate the refugia discovered in this study 


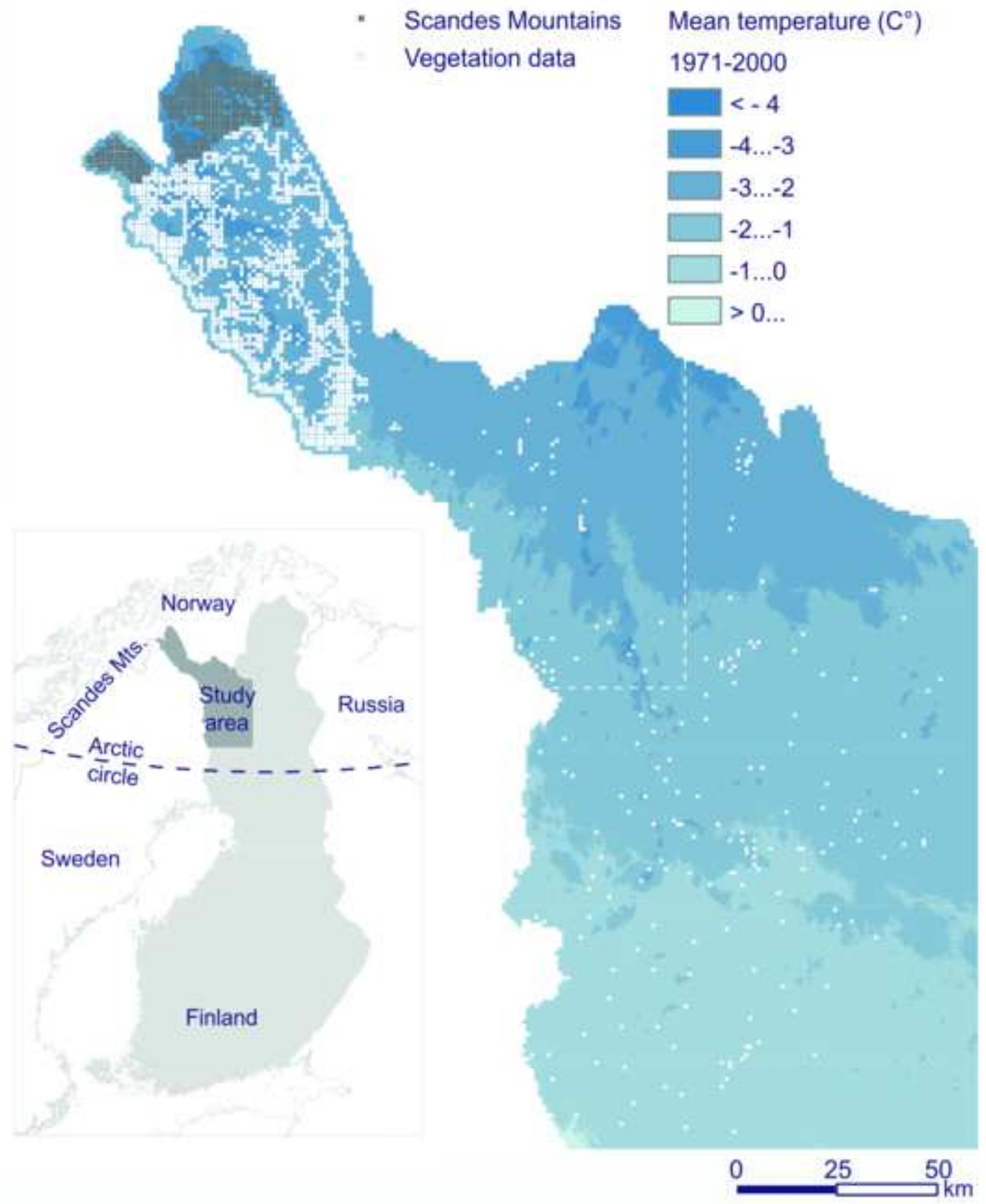


1) Refugk a) distribution, b) spedes ichness = $6 D D 3+F D D+W A B+7 \max +T m h$

(cinistomodil)

II) Refugia a) distrlbution, b) specles richness = cllmato modal + TWI + slope + rodfotion [dinces + topography noded] il) Refugka a) distrlbution, b) spedes ichness = clmate model+ roak cover + soif diversity + colcoreousness [clineso + coolocy model])

b) Rafinda a) distrlbution, b) species nchness -

dlmite model + $\pi W /+$ slope + rodition + rock cover + soll dhuarsty + culcareousness

(tril modin') 
Figure

Click here to download high resolution image

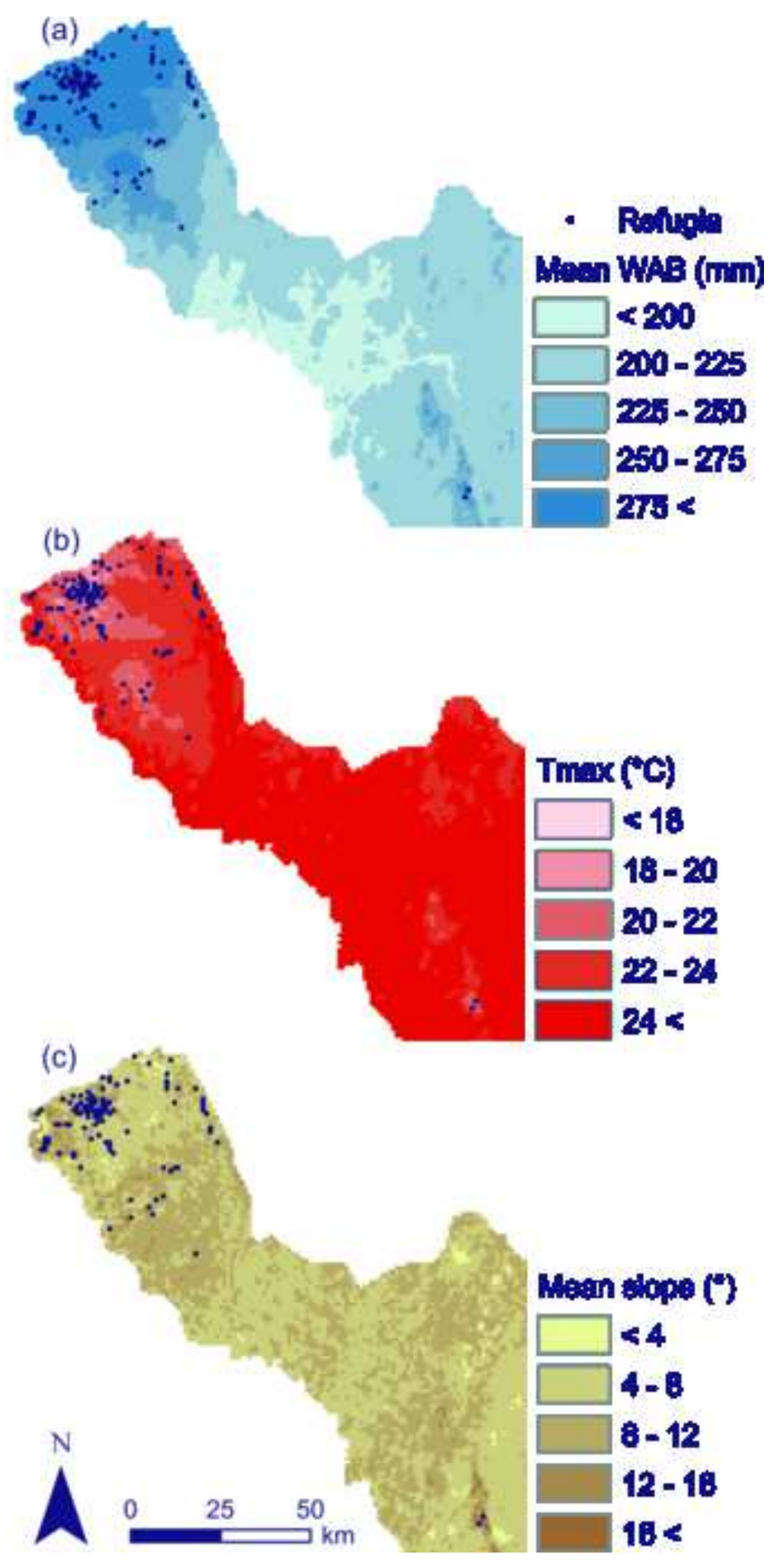


(a)

\begin{tabular}{cc}
\multicolumn{2}{c}{ (1) Cllmato-only } \\
\hline AUC & TSS \\
\hline 0.8563 & 0.5772 \\
\hline
\end{tabular}

(i) Cllmate + topography AUC TSS $0.8644^{\cdots+1} 0.5989^{m+\cdots}$ \begin{tabular}{c} 
(II) Cllmate + geology \\
$\frac{\text { AUC }}{\text { TSS }}$ \\
\hline $0.8555 n$ S $0.5844^{* * t+1}$ \\
\hline
\end{tabular}

(v) Full model

$\frac{\text { AUC }}{\text { TSS }}$

(b)

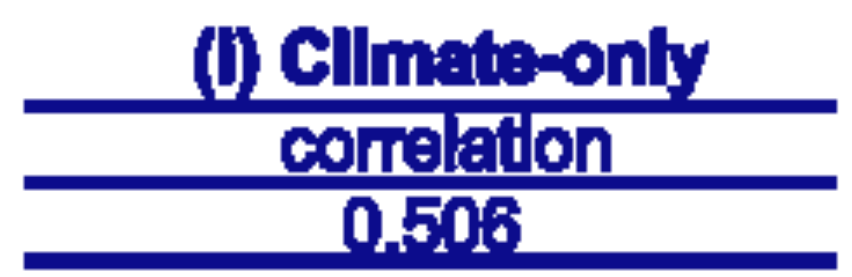

(il) Cllmats + topography comelation $0.5064^{*}$
(III) Cllmate + geology correlation 0.5049 ns

(v) Full model

correletion

$0.5066 n \mathrm{~s}^{\mathrm{t}}$ 

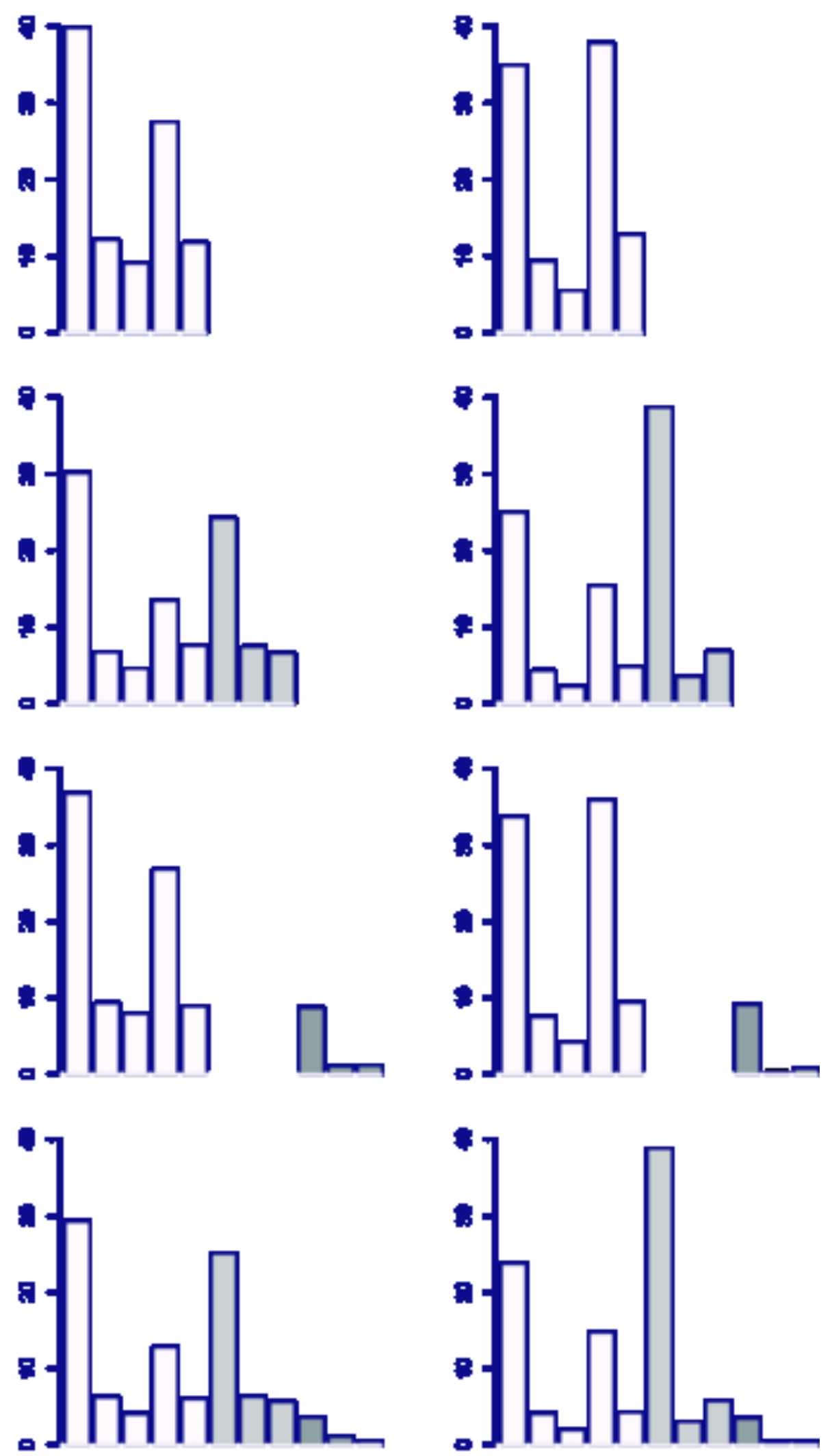
Click here to download high resolution image

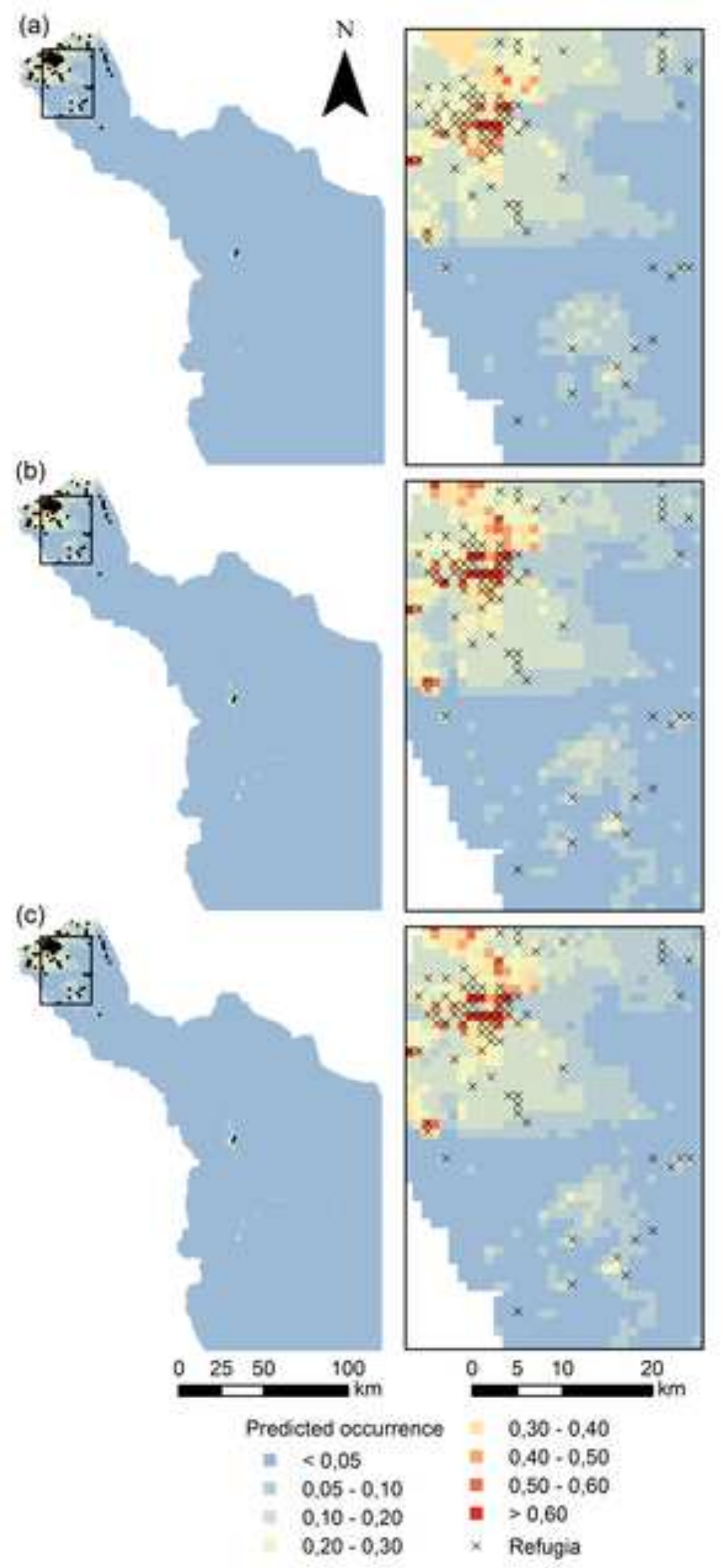




\begin{tabular}{|c|c|c|c|c|c|c|}
\hline Category & Variable & Description & Unit & Mean & Min & Max \\
\hline \multirow[t]{5}{*}{ Climate } & GDD3 & Growing degree days (accumulated daily temperature sum above $3^{\circ} \mathrm{C}$ ) & ${ }^{\circ} \mathrm{C}$ & 623.6 & 267.7 & 1117.6 \\
\hline & FDD & Freezing degree days (accumulated daily temperature below $0^{*} \mathrm{C}$ ) & "C & -1794.9 & -2062.5 & -1536.9 \\
\hline & WAB & Water balance ( $\Delta$ annual precipitation sum vs. potential evapotransipiration) & $\mathrm{mm}$ & 259.3 & 191.9 & 368.2 \\
\hline & Tmax & Lowest absolute maximum temperature & ${ }^{\circ} \mathrm{C}$ & 23.4 & 18.6 & 27.4 \\
\hline & Tmin & Lowest absolute minimum temperature & ${ }^{\circ} \mathrm{C}$ & -32.1 & -42.4 & -24.3 \\
\hline \multirow[t]{3}{*}{ Topography } & Slope & Slope angle & Degree & 8.0 & 1.1 & 22.9 \\
\hline & Radiation & Potential annual direct radiation & $\mathrm{MJ} / \mathrm{cm}^{2} / \mathrm{a}$ & 0.43 & 0.28 & 0.59 \\
\hline & TWI & Topographic wetness index & Index & 6.9 & 5.7 & 7.9 \\
\hline \multirow[t]{3}{*}{ Geology } & Calcareousness & Cover of calcareous substrates & $\%$ & 8.1 & 0 & 49.6 \\
\hline & Soil diversity & Presence of peat, rock, sand and/or silt & Numeric & 2.9 & 1 & 4 \\
\hline & Rock cover & Cover of rocks & $\%$ (scaled) & 0 & 0 & 1 \\
\hline
\end{tabular}


Electronic Supplementary Material
Click here to download Electronic Supplementary Material: OnlineResource_1.pdf

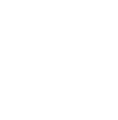

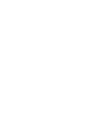

$\sqrt{10}$

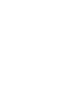

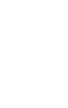
.

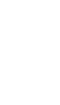

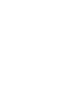

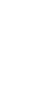

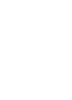

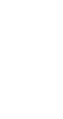
. . .

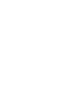

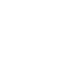

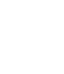

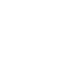

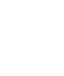

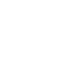

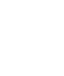

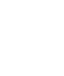

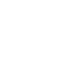

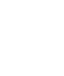

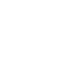

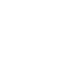

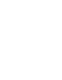

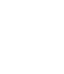
更

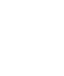

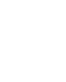

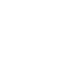

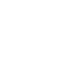

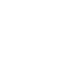
(

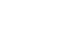
(n) (1) 
Electronic Supplementary Material
Click here to download Electronic Supplementary Material: OnlineResource_2.pdf

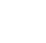

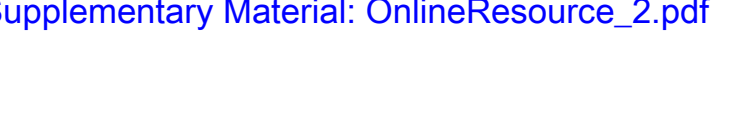

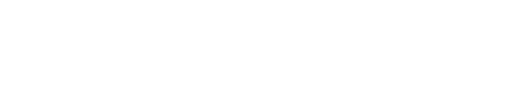

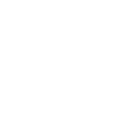

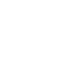

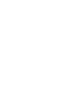

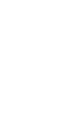

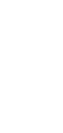

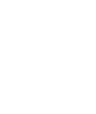

.

-

-

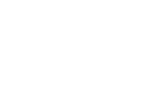

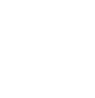

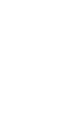


Electronic Supplementary Material
Click here to download Electronic Supplementary Material: OnlineResource_3.pdf

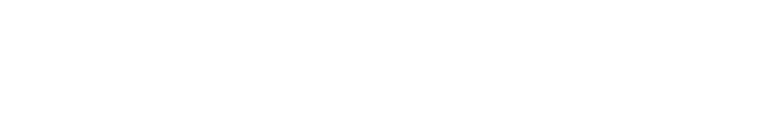
. (1) (1) (1) (1) (1) (1) (1) (1) (1) (1) (1) . . . . . . . . . . . . . . . . 
Electronic Supplementary Material
Click here to download Electronic Supplementary Material: OnlineResource_4.pdf

.

$\sqrt{2}$

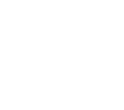

(a)

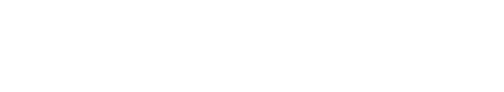

